\title{
Os sentidos da atenção domiciliar no cuidado ao idoso na finitude: a perspectiva humana do profissional do SUS
}

\author{
The meanings of home care in caring for the older person \\ at end-of-life: the compassionate perspective of the professionals \\ from SUS
}

Fernanda Pasquetti Marques (https://orcid.org/0000-0002-8094-951X) ${ }^{1}$

Alexandre Fávero Bulgarelli (https://orcid.org/0000-0002-7110-251X) ${ }^{2}$

${ }^{1}$ Departamento de Odontologia Preventiva e Social, Universidade Federal do Rio Grande do Sul (UFRGS). Av. Paulo Gama 110, Farroupilha. 90040-060 Porto Alegre RS Brasil.

fernanda.pasquetti@ gmail.com

2 Programa de PósGraduação em Saúde Coletiva, Escola de Enfermagem, UFRGS. Porto Alegre RS Brasil.

\begin{abstract}
The access to healthcare of elderly individuals in their twilight years needing palliative care in the home serve as a wake-up call in terms of current healthcare programs and strategies. This study aims to understand the meanings of domiciliary care in the scope of actions of primary health care regarding the older person at the endof-life, from the perspective of the SUS workers. Qualitative theoretical and methodological approach study, with a comprehensive research design, from the main thoughts of the German philosopher Hans-Georg Gadamer, with 12 subjects. Data were systematized and analysed according to the Content Analysis and interpreted through the Hermeneutics philosophy. It is understood that domiciliary care and visits are something distressing, but effective and generating human processes of trust and collective articulations for care in respect to the other condition. The consensual perception of domiciliary visits encompasses the dialogic reflection of the representation of the compassionate care in working at SUS. It is believed that this study will make it possible for primary care managers to reflect on how important, necessary, and harrowing is the development of home care among all Brazilian realities.
\end{abstract}

Key words Health of the Elderly, Domiciliary Care, Palliative Care, Unified Health System
Resumo O acesso aos cuidados em saúde de usuários idosos que se encontram em processo de finitude e em necessidades paliativas no domicílio servem de alerta para programas e estratégias de cuidado em saúde. Objetiva-se com este estudo compreender os sentidos da atenção domiciliar no escopo das ações da atenção primária no cuidado a estes idosos pela perspectiva do profissional da saúde do SUS. Estudo de aproximação teóricometodológica qualitativa, com desenho de pesquisa compreensivista partindo-se dos pensamentos do filósofo alemão Hans-Georg Gadamer, com doze profissionais. Os dados foram sistematizados e analisados segundo a Análise de Conteúdo e interpretados por meio da Hermenêutica filosófica. Compreende-se que a atenção domiciliar ao idoso como algo angustiante, porém efetivo e gerador de processos humanos de confiança e articulações coletivas para o cuidado em respeito a condição outro. O sentido da atenção domiciliar abarca na reflexão dialógica da representação do humano $e$ da solidariedade no exercício do trabalho no SUS. Acredita-se que este estudo possibilitará um norte para que os gestores da atenção primária reflitam sobre o quão importante, necessário e angustiante é a realização de atenção domiciliar nas realidades brasileiras.

Palavras-chave Saúde do idoso, Assistência domiciliar, Cuidados paliativos, Sistema Único de Saúde 


\section{Introdução}

O envelhecimento populacional brasileiro demanda investimentos na construção de novas formas de cuidados prolongados no domicílio e de Atenção Domiciliar/AD dentro das ações ofertadas pelos serviços públicos de saúde ${ }^{1}$. A AD é fundamental para a integralidade do cuidado, e permeada por um conjunto de ações no domicílio do usuário de maneira continuada e integrada à rede assistencial do Sistema Único de Saúde/ SUS $^{2}$. As visitas domiciliares mostram-se como uma ferramenta de cuidado integral, uma técnica de intervenção em saúde bem como algo que aproxima a família do serviço de saúde e do profissional de referência para o cuidado de quem se encontra vulnerável ${ }^{3}$. É na visita domiciliar que se identificam reais contextos de envelhecimento dos usuários, necessidades de cuidados paliativos, da identificação de fatores de resiliência, bem como da identificação das relações familiares importantes no processo de cuidado em saúde ${ }^{1,2,4,5}$.

O SUS dentro da gama de seus programas, políticas e modelos assistenciais será fundamental para uma nova fase da velhice que está por vir, em que o aumento no número de idosos em idades muito avançadas trará consigo demandas complexas de serviços de saúde ${ }^{6}$. Uma destas demandas necessárias é o preparo de profissionais da saúde para o enfrentamento das realidades da $\mathrm{AD}$, os quais se deparam com incongruências entre a política e o cenário dos modelos assistenciais dos municípios ${ }^{7}$. Deste modo o enfrentamento da finitude por causas naturais e pelo próprio tempo ${ }^{8}$, bem como a terminalidade por doenças letais, é algo a ser pensando e trabalhado pela articulação entre suporte social, profissionais do SUS e cuidados paliativos. Não compreendemos cuidados paliativos apenas como uma alternativa de cuidado de morbidades de pacientes oncológicos, mas, também, como uma das necessidades de atenção integral à saúde das populações em situações de comorbidades de várias doenças crônico-degenerativas bem como condições de velhice muito avançadas ${ }^{4,9-11}$.

A realização de cuidados paliativos nestas dimensões e o conforto da família do idoso em paliação são situações que podem ser ofertadas também pelo modelo de assistência à saúde que inclui em suas práticas a oferta da $\mathrm{AD}$. A AD promove a aproximação do profissional de saúde como o idoso e família por meio de visitas domiciliares e deste modo existe uma aproximação com a realidade de vida do idoso e a coordenação para a otimização do cuidado ${ }^{1,12,13}$.
Diante tais pressupostos, e acreditando na importância da percepção dos profissionais do SUS que realizam a atenção domiciliar nos seus territórios de atuação, objetivamos compreender os sentidos da atenção domiciliar no escopo das ações da atenção primária no cuidado de idosos na finitude.

\section{Metodologia}

Este é um estudo com abordagem teórico-metodológica qualitativa, e desenho de pesquisa compreensivista fundamentado no referencial teórico da Hermenêutica Filosófica de Hans-Georg Gadamer ${ }^{14}$. Buscamos interpretar as percepções de profissionais da atenção primária em relação à realização das visitas domiciliares, para construir uma forma de compreender sentidos, emoções e práticas da $\mathrm{AD}$ frente à finitude de idosos.

Realizamos a pesquisa a partir de entrevistas com profissionais da saúde trabalhadores do SUS dentre eles médicos, enfermeiros e dentistas, atuantes no distrito de saúde docente-assistencial da Universidade Federal do Rio Grande do Sul, na cidade de Porto Alegre/RS. As entrevistas foram realizadas de forma individual, nas Unidades de Saúde em que os profissionais trabalhavam, sendo previamente agendadas em horários propostos pelos entrevistados de modo a garantir privacidade aos mesmos. Seguimos um roteiro norteador com perguntas de cunho hermenêutico, que foi preliminarmente articulado com questões que abordassem o significado da visita domiciliar, as dificuldades e as potencialidades encontradas bem como a relação com os cuidadores e familiares dos idosos. Além disso, abordamos a necessidade de conhecimento sobre políticas públicas sobre atenção domiciliar e a Rede de Atenção à Saúde do município, bem como a questão do enfrentamento da finitude/terminalidade no caso de usuários idosos acompanhados pela Unidade de Saúde.

Para a coleta de dados entrevistamos uma cota de sujeitos que no montante final nos permitiu atingir uma densidade de informação que fizessem com que atingíssemos nosso objetivo. Deste modo, optamos pela saturação de informação ${ }^{15}$ e saturação de participantes/informantes por meio da técnica Snow-ball sample ${ }^{16}$. Esta técnica nos permitiu formar cadeias de referências e seguir um processo de saturação de informantes chaves o qual permitiu a finalização de uma cota de 12 profissionais entrevistados ${ }^{16}$. Inicialmente, entrevistamos um profissional que foi indicado pela Gerencia do Distrito Docente Assistencial. 
Em seguida este profissional indicou outro para participar e assim sucessivamente. Durante este processo, todas as entrevistas eram transcritas e lidas exaustivamente para buscarmos pontos de saturação das informações de acordo com o objetivo do estudo. Encerramos a coleta quando atingimos a profundidade de informação necessária e o esgotamento de informantes chaves. Para atingirmos esta cota final de participantes, fomos entrevistando os profissionais indicados seguindo os seguintes critérios de inclusão: profissionais com mais de dois anos de trabalho nos serviços da atenção básica do SUS; médicos, dentistas e enfermeiros que faziam parte de equipes de saúde da família/eSF do distrito; bem como profissionais que realizavam atenção domiciliar na modalidade tipo $1 / \mathrm{AD} 1^{17}$.

Analisamos os dados de modo articulado com a construção de categorias temáticas. Tal construção ocorreu por meio da sistematização de dados com a técnica da Análise de Conteúdo que nos permitiu construir categorias iniciais, a partir de indícios interpretativos presentes no conteúdo das falas, para estruturar nossa descrição e interpretação ${ }^{18}$. Ao longo deste processo nossas inferências foram fundamentadas em nossas concepções pré-estabelecidas, associando-se com a história e os contextos presentes na percepção dos profissionais. Assim, buscamos compreender o sentido da realização de visitas domiciliares lendo, analisando e interpretando algo emergente nos textos que representam algo que os profissionais nos apresentam sobre o objeto de estudo. Nesta escolha que fizemos, nós analisamos o consenso social com o suporte do movimento interpretativo da hermenêutica filosófica de Hans-Georg Gadamer ${ }^{14}$. Para estruturar nosso processo interpretativo, apresentamos alguns trechos de falas com grifos de indícios interpretativos que nos levaram a compreender o possível consenso destes profissionais sobre os sentidos atribuídos ao exercício da atenção domiciliar.

O presente estudo teve sua realização aprovada pelo Comitê de Ética em pesquisa da Universidade XX, e auxílio financeiro da Fundação de Amparo à Pesquisa do Estado do Rio Grade do Sul/FAPERGS.

\section{Resultados e discussão}

Apresentamos os resultados e os discutimos trazendo um apanhado geral e em sequência duas categorias temáticas que, articuladas entre si e entrelaçadas com indícios interpretativos da perspectiva do profissional, permitiram a construção de compreensões sobre o objeto de estudo com nossas inferências fundamentadas na hermenêutica Gadameriana.

Mesmo dentro de um cenário loco-regional, trazemos uma construção social que se traduz em indícios para compreendermos as angústias dos profissionais dentro dos sentidos da visita domiciliar na finitude de usuários idosos. Para o presente estudo, não houve distinção entre as três categorias profissionais por partimos do pressuposto que é atribuição de todos estes profissionais da atenção básica realizar a atenção domiciliar e fazer parte da equipe multiprofissional para realização de cuidados paliativos quando necessários ${ }^{1,17}$. Entrevistamos sete enfermeiros, dois dentistas e três médicos, em sua maioria mulheres. Todos eram especialistas em diferentes áreas incluindo; Saúde Pública, Saúde da Família e Saúde do Trabalhador. Os profissionais possuíam entre dois e oito anos de atuação na Atenção Primária à Saúde do município, e dispunham de ao menos um turno semanal reservado para atividades de atenção domiciliar. A atuação destes profissionais ocorriam em Unidades de Saúde da Atenção Primária do distrito estudado, tais unidades são compostas por uma ou duas Equipes de Saúde da Família e equipe mínima de Saúde Bucal.

O cuidado em saúde na velhice avançada dentro de um quadro de finitude é uma realidade de enfrentamento de diversos profissionais da atenção primária em saúde. Estes idosos frágeis que necessitam de cuidados paliativos com medidas de conforto recebem tais cuidados em casa por profissionais preparados e sensibilizados. Os cuidados paliativos referem-se a uma abordagem de cuidado em saúde para melhorar condições de vida por meio de alívio de sofrimento e conforto emocional para pacientes e familiares em casos de situações de risco de vida e proximidade com a morte $^{19}$. Neste caso, são os profissionais da atenção básica que compreendem emocionalmente o momento do outro, de sua família e da rede de cuidado. Assim, a compreensão, destes profissionais, parte da premissa de olharmos para a totalidade das relações dentro do que é vivido por todos os envolvidos em um fenômeno e não apenas por um sujeito envolvido com o fenômeno ${ }^{14}$.

Observamos que de modo geral a sobrecarga de atribuições, a falta de profissionais e de tempo para aperfeiçoamento representam uma forma de supressão de potencialidades dos entrevistados. Além disso, inúmeros foram os relatos que 
indicaram a dificuldade de acessibilidade devido às condições adversas dos territórios e da violência cotidiana como marcos do contexto de trabalho desses indivíduos. Apontamos neste estudo que os profissionais são capacitados para o enfrentamento da prática e, ao mesmo tempo, angustiados por não conseguirem construir uma rede de paliação para seus usuários idosos devido a limitações de recursos e planejamento, presente na rede de prestação de serviço do SUS. Muitas vezes uma prestação de cuidado primário, como a paliação desenvolvida por meio da atenção primária, desorganizada e desarticulada de outros modelos assistenciais gera limitações para a coordenação do cuidado ${ }^{20}$, e isto vai refletir na ação do profissional.

A partir da visita de um profissional da saúde do SUS ocorre, também, a concretização da empatia humana que molda as práticas assistências de cuidado dentro do entendimento do difícil momento do outro e da continuidade do cuidado social. O cuidado deve ser pensado e realizado conjuntamente e o profissional tem a competência técnica para que o processo da finitude seja vivido dignamente ${ }^{21}$.

\section{A atenção domiciliar gerando angústias no cuidado de um idoso na finitude}

A temporalidade é a dimensão mais comum a todos os seres e como reflexo, a finitude é o momento que se dá ao final da existência de um $\operatorname{ser}^{21}$. Vivenciar o momento de finitude do outro sob seus cuidados, agrega vários aspectos emocionais e técnicos permeados por contextos que fazem com que as relações de trabalho em saúde nas práticas da atenção primária, mostram-se fundamentais para serem pensadas e discutidas na atualidade. Somando-se a estes fatos, compreendemos que existe na filosofia de Gadameriana um reflexo do pensamento de Martin Heidegger que nos diz que o tempo influencia na interpretação do ser pois, a relação com a natureza do objeto contextualizado na temporalidade aponta o sentido ontológico do mundo a nossa volta ${ }^{22}$.

A angústia do profissional pode estar associada a não articulação das suas ações de cuidado no domicílio com outros níveis da rede de atenção. Este aspecto faz com que profissionais da atenção primária à saúde vivenciem os contextos de cuidados em usuários com doenças de curso letal que provocarão sofrimento dentre tantos sentimentos envolvidos no exercício da profissão $0^{23}$. Os profissionais que realizam atenção domiciliar enfrentando cuidados de idosos na finitude, suscitam melhorias organizacionais na rede de prestação de serviço do SUS do município em que atuam.

Sabemos que em casos de finitude os cuidado paliativos são fundamentais e necessitam de modelo de atenção específico ${ }^{24}$. O modelo de atenção em saúde em que os profissionais se aproximam das famílias é o eixo condutor do cuidado, e mostra-se como fundamental para que o profissional seja um elo concreto entre a família, ou a rede de cuidado que envolve o idoso em sua finitude, e o serviço de saúde. Dentro da rede assistencial do município, cenário deste estudo, a atenção domiciliar articula-se pela estratégia de saúde da família ou pelo Programa Melhor em Casa ${ }^{2,17}$, e nesta articulação alguns são os desafios apresentados pelos trabalhadores. De certa forma, os desafios trazem angústias. A não efetividade da rede em articular as demandas com seus recursos de consumo apontam situações que trazem uma reflexão sobre a sustentação desta rede em relação a sua capacidade de atender as demandas de pacientes na finitude em casa.

...essa rede ela tem que ser sustentada... muitas vezes "ah, é um curativo!", na minha área assim; ; ; Mas as pessoas não tem material, né? Então, tu também se sente; ; (pausa e gestos de dúvida). A gente precisa desse fortalecimento da rede em todos os sentidos, sabe? Capacitação, de fazer com que a rede se ligue mais, que realmente as unidades da Atenção Básica façam essa visita, né? Entrevista 9/ seq.03

O desabafo deste profissional nos mostra indícios interpretativos que dentro de um processo hermenêutico de leitura e interpretação nos apresentam a angústia como um sentimento vivo na prática da visita domiciliar e está relacionada com o fato do profissional se sentir sem as ferramentas e o suporte da rede de atenção para cuidar do idoso. O indício interpretativo "Então, tu também se sente; ; ; (pausa e gestos de dúvida)" mostra que a falta de recursos simples faz com que o trabalhador se sinta impotente e não consiga resolver o problema do usuário sem uma rede efetiva. Acreditamos que o profissional tem razão, pois para um serviço de saúde ser realizado com qualidade, as instalações, a infraestrutura e os recursos devem estar ajustados com a demanda. A angústia pela impossibilidade de fazer algo para o usuário na finitude, além da paliação, é algo presente no exercício profissional da atenção domiciliar, também, em casos onde falta recursos físicos e humanos preparados ${ }^{23}$. O trabalhador precisa estar conectado com as circunstâncias da prestação do serviço e suas ações devem estar conectadas com seu conhecimento técnico. É como um movimen- 
to hermenêutico de antecipação da completude de ideias e conhecimentos, trazidas também por outros profissionais que nos permitem essa inferência. É essa idiossincrasia que apresenta a realidade de comportamentos ${ }^{25}$, reações emocionais frente à angústia e às percepções de necessidade de melhorias de grupos que vivenciam um mesmo contexto particular como o grupo de profissionais da atenção domiciliar estudado.

Em conformidade ao compreendido sobre a rede assistencial, angústias surgem também pelo fato do profissional ser um elo entre o usuário totalmente dependente e o serviço. Este elo traz consigo a responsabilidade profissional que acontece dentro de um espaço íntimo de prestação de serviço da saúde ${ }^{23}$. Dito de outra forma, o profissional adentra a casa do usuário e durante a assistência em saúde vivencia emoções contextualizadas na realidade presenciada no momento, que são perceptíveis em textos ${ }^{26}$ transcritos das falas. Neste caso, o profissional vive certo mimetismo com suas emoções, pois ajusta sua realidade emocional com a realidade emocional da família e ou dos cuidadores do idoso sob sua assistência. Este mimetismo é algo fundamental para ser analisado para a construção de uma compreensão sobre a verdade vivenciada deste objeto de pesquisa ${ }^{26}$.

Pensando como Gadamer ${ }^{26}$, o qual nos apresenta a possibilidade de compreensão de mundo por meio da linguagem do consenso que nos traz sentidos a serem interpretados, destacamos estes dois trechos:

Mas foi muito sofrimento assim, porque a gente via que em casa a idosa estava sofrendo muito e precisaria de muito mais conforto. E aí aonde eu fiquei mais angustiada e aí eu encaminhei para o hospital mesmo, porque eu via que a usuária estava com muita dor. Entrevista 3/seq. 08

Mas é; ; ; é; ; ; angustiante da gente não poder fazer mais. Se tivesse; ; ; não sei, se fosse mais, se tivesse algum; ; ; não sei, se fosse mais isso divulgado, disseminado, investido na saúde na questão também de paliativo. Eu acho que ainda tem pouco, né; ; ; Enfim; ; ; É isso (pausa). Entrevista 1/seq. 02

Eu vivi, agora a pouco, conversei com a sobrinha que era quem cuidava, enfim; ; era bem cuidados paliativos mesmo, assim; ; ; a gente via que a família na medida do possível cuidava bem daquela usuária ali, a gente sempre orientando medidas de conforto, né; ; ; gente tinha essa usuária sofrendo muito em casa. A gente com uma agonia assim; ; ; . Entrevista 12/seq. 01

Os trechos trazidos apresentam situações reais de vivência do exercício profissional que nos permitem observar o algo vivido em comum que é a visualização do sofrimento do outro. É possível identificar indícios de que um grupo de pessoas, no caso a equipe que realiza a atenção domiciliar, vê o sofrimento do usuário idoso na finitude e a necessidade de investimentos nos cuidados paliativos destes usuários. Segundo Silva et al. ${ }^{27}$, estas equipes devem trocar informações e conhecimentos para o desenvolvimento profissional e melhorias das ações de cuidado.

Observamos a questão da angústia, também, na oralidade dos textos quando muitas pausas, pensamentos e questionamentos vagos estão presentes. Este é um reflexo do "não dito" trazido, também, por outros profissionais. O trabalhador busca uma completude para uma efetiva atenção domiciliar no caso da finitude, onde apenas a paliação é a medida de cuidado e conforto neste momento do usuário.

O território de atuação destes profissionais contava com um relativo número de idosos acamados e dependentes que necessitavam de cuidados paliativos, visto que se encontram na terminalidade consequente de doenças degenerativas e/ou malignas. Estas condições acarretam a necessidade de cuidados paliativos e medidas de conforto dentro de cuidados integrais que devem fazer parte da agenda da gestão do município e de políticas públicas voltadas para a paliação ${ }^{19}$. Deste modo, o desafio apresentado incipientemente na perspectivas destes trabalhadores é a incorporação de um modelo assistencial de cuidados paliativos na pratica assistencial da rede $^{12,28}$. Na fala supracitada, é possível perceber o indício interpretativo: "investido na saúde na questão também de paliativo", que nos mostra a possível falta de investimento neste modelo assistencial tão importante nas situações de cuidado para evitar a ruptura da continuidade de acompanhamento destes idosos em que o que deve ser feito e a paliação.

Conforme nos mostra Gadamer ${ }^{14}$, sabemos que as pessoas trazem consigo concepções e entendimentos sobre o todo vivido coletivamente. Seguindo na perspectiva hermenêutica filosófica é possível observar que o profissional ao refletir sobre seus conceitos pré-estabelecidos relacionados a este exercício profissional, o não dito norteia um consenso de que é preciso fazer algo em relação a desarticulação com a rede assistencial e com este vazio de não poder fazer nada mais além da paliação. Talvez a paliação bem coordenada dentro de uma rede seja a melhor opção de cuidado na finitude de idosos visto que a atenção domiciliar, dentro da condição de ser uma 
política pública, é considerada um dispositivo de segurança ao usuário. Muitas vezes o domicilio é um local de cuidado em saúde que com as adequadas tecnologias ofertadas pela equipe, com o conforto da família, e pelo fato dos idosos estarem distante de possíveis infecções hospitalares mostra-se como um efetivo local de cuidado ${ }^{29}$.

Após estas projeções de significados, para compreendermos o todo internamente constituído neste grupo de profissionais e seguindo um pensamento hermenêutico ${ }^{14}$, trazemos a fala de um profissional que nos reitera indícios de desgaste emocional disparador de soluções técnicas que não deixam de gerar angústia.

... eu não podia ver a criatura sentindo dor, tomando tudo que era medicação. E aí foi que ela foi encaminhada até pro hospital... e aí dois dias depois ela foi à óbito assim; ; ; Mas; ; ; foi bem desgastante no sentido de; ; ; assim sem recurso mesmo, assim pra dar aquele conforto pra aquela paciente assim... Entrevista 12/seq. 08

eu não aguentava mais ver::: porque era uma usuária que várias vezes ia para o serviço de emergência, era liberada com; ; ; muita dor; ; ; tipo assim, não tem mais nada pra fazer, vai pra casa pra vir a morrer sob nossos cuidados; ; ; mesmo. Entrevista $05 /$ seq. 03

Muitas vezes a $\mathrm{AD}$ traz angústias pela própria ineficiência da rede em articular os cuidados paliativos em casa com apoio e, também, pela própria situação emocionalmente frágil e "bem desgastante" e difícil de ser encarada como é a finitude de um ser humano envelhecido em processo de dor impossível de ser controlada e levando a hospitalização. Muitas vezes a angústia e o sofrimento do profissional que realiza cuidados paliativos está associada a dificuldade de organização em rede do serviço, problemas em administrar emocionalmente a família bem como vivenciar o sofrimento do paciente em paliação ${ }^{30}$. Os achados mostram que alguns dos sentidos da atenção domiciliar no escopo das ações da atenção primária à saúde no cuidado de idosos na finitude podem ser a angústia e o sofrimento, porém este modelo de assistência traz algumas potencialidades para o profissional que se refletem no aspecto humano do cuidado e do vínculo com o serviço de saúde.

\section{Atenção domiciliar como potente ferramenta humana de cuidado e confiança}

Continuamos nossa interpretação dos sentidos da atenção domiciliar na finitude de usuários idosos partindo de uma condição que é a pre- sença de ações de atenção primárias fortalecidas no município e a presença da atenção domiciliar como algo real no exercício profissional destes profissionais da rede do município. Deste modo nossa caminhada interpretativa, conforme nos diz Gadamer ${ }^{14,26}$, segue um indicativo prévio da existência de uma perspectiva que é a presença de modelos de prestação de serviços que incluem a visita domiciliar na sua rotina destes profissionais. Deste modo o consenso atingido perpassa pela realidade da atenção primária do município.

Independente do modelo de atenção à saúde em que um profissional esteja vinculado, a questão do cuidado de pacientes próximos da morte mostra-se como algo complexo de ser trabalhado. Tal complexidade muitas vezes está associada à identificação, por parte da equipe de saúde, família e possíveis cuidadores, das reais necessidades físicas e psíquicas que o paciente precisa nesta fase de sua vida para um conforto e qualidade de morte. O conceito de qualidade de morte refere-se ao conjunto de cuidados construídos em conjunto com familiares e/ou cuidadores para uma melhor qualidade de vida neste complexo momento de finitude de acordo com as experiencias, as expectativas e os valores atribuídos à morte de um ente querido ${ }^{31,32}$. A realização de cuidados paliativos em conjunto com familiares e cuidadores mostra-se diretamente associados a uma qualidade de morte ${ }^{8,33}$. É possível observar que a proximidade com a família cria um vínculo humano de empatia, também, por parte do profissional que busca conhecer a realidade de quem necessita de cuidados paliativos, em um contexto de qualidade de morte, e deste modo orientar e confortar os cuidadores ao redor deste usuário. Lembramos que Heidegger ${ }^{8}$, nos mostra que o cuidar, acima de tudo, é a base do ser humano.

... tu poder prestar um atendimento... tu poder orientar não só aquele usuário, mas tu orientar todos os cuidadores, né? é adequar aquilo que a gente muitas vezes fala num ambulatório, num hospital e que tá totalmente fora da rotina da pessoa na vida real dela de domicílio, então eu acho que essa... coisa humana... de tu realmente conhecer a realidade... a necessidade... Entrevista 9/seq. 04

Um idoso na finitude pela extrema velhice ou um jovem na terminalidade por alguma doença letal são pessoas com uma vida própria, única $\mathrm{e}$ singular ${ }^{34}$. Na compreensão da singularidade desta fase da vida, podemos dizer que $\mathrm{o}$ ato de visitar a residência de um usuário, e estabelecer um processo de cuidado respeitando suas necessidades, é algo que situa a atenção domiciliar como uma ferramenta que extrapola a dimensão técnica do 
cuidado e mostra-se como uma ferramenta, também, humana. É humana, pois para que aconteça de maneira efetiva é necessária a empatia do profissional da saúde para com o usuário do serviço e sua família. Percebemos este consenso de empatia nos profissionais estudados quando os mesmos apresentam a importância do vínculo para entender a realidade e propor mudanças quando possível para melhorar a qualidade de vida e de morte do usuário.

... eu acho que uma das maiores vantagens assim do cuidado domiciliar; ; ; do cuidado no seu ambiente, no seu domicílio é imaginar que aquela pessoa viveu não sei quantos anos naquele local, no seu ambiente, onde ela está com a sua família; ; ; por exemplo... vai consultar com a nutricionista, orienta dietas com coisas caras, que tu sabe que a família não vai comprar. Então eu acho que essa, pra mim; ; ; eu vejo como a maior vantagem da atenção domiciliar... de tu conhecer realmente a realidade daquele indivíduo. Entrevista 2/seq. 03

Mas acho que o grande ganho é o profissional ver as necessidade, ver o ambiente que está aquele idoso, reconhecer até onde a gente pode atuar com ele de acordo com o ambiente dele. Adaptar o ambiente dele de acordo, às necessidades que ele tem também... Daí a gente vai fazer uma visita e a gente vê que o idoso não tem nem como tomar banho, né; ; ; então acho que reconhecer as fragilidades do ambiente dele e poder adaptar o tratamento dele $e o$ reforço do vínculo... Entrevista 8/seq. 05

Adentrar a realidade da finitude de usuário, ser recebido no domicilio e desenvolver seu papel de profissional da saúde que está lá para oferecer a melhor possibilidade de cuidado é uma aproximação humana vista como algo favorável e enriquecedor para o profissional. O "grande ganho" apresenta-se como algo acrescentado no ato de cuidar deste profissional e reflete-se como o respeito e as adaptações com a realidade para uma melhor qualidade de morte deste idoso. Cuidar é mais que um ato, é uma atitude profissional ${ }^{35}$. O consenso construído apresenta a $\mathrm{AD}$ como uma prática técnica e humana, pois permite a identificação da realidade do usuário e faz com que adaptações dos cuidados nesta realidade sejam pensadas no ambiente, para a realização do cuidado de maneira otimizada. Neste caso é fundamental que o profissional tenha habilidade para ajudar a família e/ou cuidadores para lidar com novas situações surgidas de otimização dos cuidados ${ }^{12}$. Deste modo, com a fundamentação trazida por Stein ${ }^{22}$, pensamos que ao trabalhador na condição de uma pessoa que interpreta realidades do usuário é sensível a cada momento de realização deste cuidado.
No movimento filosófico de projetar percepções no todo que foi dito ${ }^{25,26}$, compreendemos que a realidade do domicílio e a adaptação de cuidados perante tal fato é algo socialmente importante na realização de uma atenção domiciliar. Para tanto, os profissionais da atenção primária do município devem participar de ações integradas na rede assistencial de modo a incorporar nas suas práticas os cuidados paliativos de idosos na finitude ${ }^{12}$. Esta incorporação é clara no cenário de práticas estudado e enriquece cada vez mais a questão humana destas relações de cuidado e de competências transversais destes profissionais ${ }^{36}$.

O contexto demográfico bem como os limites do processo de trabalho no âmbito local e certa desarticulação com a rede dentro do cenário do estudo, permitiram a percepção de um consenso de que o vínculo entre a família/cuidadores e o profissional é algo que realmente acontece em benefício do usuário idoso. Dito de outra forma, todos os entrevistados fazem parte de um município que investe na $\mathrm{AB}$ e entende $\mathrm{AD}$ como ferramenta fundamental, que necessita melhorias, para o cuidado do idoso e compreensão das necessidades sentidas pelos cuidadores familiares ${ }^{37}$. $\mathrm{Na}$ hermenêutica filosófica, compreensão sobre algo é desenvolvida, também, nas realidades dos acontecimentos em que o consenso constrói suas percepções ${ }^{26}$.

Acho que quando tu vai na casa do paciente $t u$ reforça o vínculo, né; ; Às vezes a gente chega lá, eles estão esperando a gente com café, já tão um dia antes se programando pra nos receber; ; ; . Entrevista $4 /$ seq. 10

Eu acho que; ; ; o primeiro é deles se sentirem valorizados assim, porque; ; ; quando tu recebe um profissional em casa, né; ; ; acho que eles se sentem muito mais cuidados, assim. Acho que reforça muito o vínculo da equipe com os pacientes, né; ; ; . Entrevista 4/seq. 14

O movimento de construção de um vínculo é algo muito importante de ser trabalhado na filosofia e na prática do cuidado focada na Atenção Primária à Saúde ${ }^{13}$. A própria política destaca a importância e a necessidade de aproximação entre usuário e serviço, pois assim surge a confiança que desencadeia um longo processo de cuidado e promoção em saúde. Como apresentado nas falas observa-se um movimento inverso no qual o profissional aponta a construção do vínculo partindo da visita. Muito importante, pois o ser humano que cuida vai até aquele que necessita do cuidado e deste modo acontece um reforço recíproco de vínculo e o reconhecimento pelo usuário. Acreditamos que este "reforçar o vín- 
culo" é dar mais força para uma relação humana de cuidado, genuína do profissional da saúde independente de sua categoria seja ele enfermeiro, médico ou dentista. O vínculo com o serviço, na condição de uma prática humana dotada de amor ao próximo e respeito, já seja algo percebido pelos usuários do SUS $^{38}$.

Um aspecto importante que observamos e compreendemos como parte dos sentidos da atenção domiciliar é o olhar para a finitude de um idoso como algo que se enquadra em causas naturais. Ou seja, os profissionais da atenção primária entrevistados neste estudo apontam esta característica como algo presenciado na rotina do trabalho com população mais envelhecidas como o caso do território de atuação estudado.

Como a gente trabalha com o envelhecimento na população eh::: fazendo uma atenção domiciliar... a gente tem outra questão da; ; ; que é a questão da morte por causas naturais. Entrevista 5/ seq. 10

Eu tive um paciente que, no ano passado já tem um ano que ele faleceu, foi até os cento e dois anos de vida, ele morreu de causas naturais então a gente foi:::: Eu acho que são potencialidades também de a gente estar trabalhando evitando da família estar indo fazer atestado de óbito no hospital, ou sobrecarregando né::.:. Entrevista 2/seq. 9

... fiz o acompanhamento até o fim da vida, fiz o atestado de óbito, eu que visitei o; ; visitei o paciente::: visitei depois de falecido pra constatar a morte... e como a família e o idoso já; ; ; já estava falecido, mas como a família já me conhecia, já tinha aquela confiança... Entrevista 11/seq.12

$\mathrm{O}$ ato de não "sobrecarregar" os familiares com questões burocráticas com a morte do idoso é algo percebido pelo profissional como uma ação de ajuda e empatia ao momento de quem está em sofrimento emocional com a morte do idoso, mesmo sendo por causas naturais. Compreendemos que o trabalhador ao realizar o atestado de óbito em uma visita domiciliar mostra que a $\mathrm{AD}$, também, é uma prática social de identificação humana com o momento de sofrimento do outro e uma prática para amenizar tal sofrimento. Para Silva et al. ${ }^{34}$, o profissional da saúde entende a sobrecarga da família e se identifica com isso e faz ações para amenizar o sofrimento emocional.
Nestes casos é importante que a equipe que cuida de usuários na finitude tenha capacidade de se organizar continuadamente ${ }^{12}$. Tal organização gera confiança com a família e ajuda em questões burocráticas. Além disso um profissional que realiza ações de atenção domiciliar deve transmitir segurança e conforto à família e/ou cuidadores ${ }^{12}$. Deste modo, foi possível compreendermos, pelo caminho hermenêutico ${ }^{26}$, que o consenso que envolve estes profissionais em seus meios de trabalho é de que a $\mathrm{AD}$ aponta potencialidades com algumas respostas às necessidades da família. Como nos diz Stein ${ }^{22}$, nossa compreensão está desperta nas necessidades e em cada momento interpretativo trazidos nas percepções dos sujeitos.

\section{Considerações finais}

A atenção domiciliar mostra-se como fundamental geradora de cuidado e confiança, vínculo e empatia do profissional, porém a mesma não acontece efetivamente sem uma articulação com a rede. Deste modo existem necessidades subjetivas dos profissionais para o desempenho de uma efetiva rede de cuidados em saúde na finitude de idosos. Deste modo, o presente estudo traz resultados importantes para a saúde coletiva de modo a elucidar a compreensão da densa teia de conceitos e práticas da atenção primária e o arcabouço de emoções que constituem uma visita domiciliar na difícil atualidade do SUS.

Como potencialidade, os achados apontam importantes situações que devem ser trabalhadas, pois muitas vezes os modelos de gestão municipal em saúde esquecem de olhar para os profissionais enquanto seres humanos que se angustiam com as dificuldades para fazer acontecer o que está nas politicas públicas que sustentam o SUS. Consideramos que existem novos caminhos a serem percorridos na saúde pública quando o assunto é olhar para a relação humana que existe entre o usuário do serviço público de saúde e o profissional de saúde, que, além de tratar doenças têm papel fundamental no conforto emocional dentro dos complexos contextos da metafísica da finitude de um ser humano que necessita de cuidado. 


\section{Colaboradores}

Este manuscrito foi desenvolvido por FP Marques e AF Bulgarelli, os requisitos para autoria foram atendidos. $\mathrm{O}$ manuscrito foi lido e aprovado por todos os autores.

\section{Referências}

1. Brasil. Ministério da Saúde (MS). Diretrizes para o cuidado das pessoas idosas no SUS (2014). Brasília: MS; 2014.

2. Brasil. Ministério da Saúde (MS). Caderno de atenção domiciliar. Brasília: MS; 2012.

3. Rocha KB, Conz J, Barcinski M, Paiva D, Pizzinato A. A visita domiciliar no contexto da saúde: uma revisão de literatura. Psicologia, Saúde \& Doenças 2017; 18(1):170-185.

4. Gómez-Batiste X, Murray SA, Thomas K, Blay C, Boyd K, Moine S, Engels Y. Comprehensive and integrated palliative care for people with advanced chronic conditions: an update from several European initiatives and recommendations for policy. J Pain Symptom Manage 2017; 53(3):509-517.

5. Mello DRB, Apratto Júnior PC, Oliveira César TP, Souza D, Miranda D, Freitas G, Leite LC. Fatores de resiliência no envelhecimento verificados na visita domiciliar: relato de uma experiência na atenção básica. REINPEC-Revista Interdisciplinar Pensamento Científico 2017; 2(2):1-4.

6. Dantas IC, Junior EPP, Medeiros KKAS, Souza EA. Perfil de morbimortalidade e os desafios para a atenção domiciliar do idoso brasileiro. Revista Kairós: Gerontologia 2017; 20(1):93-108.

7. Forte ECN, De Pires DEP, Scherer MDA, Soratto J. Muda o modelo assistencial, muda o trabalho da enfermeira na Atenção Básica? Tempus Actas de Saúde Coletiva 2018; 11(2):53-68.

8. Heidegger M. Ser e Tempo. Petrópolis: Vozes; 2009.

9. Smedbäck J, Öhlén J, Årestedt K, Alvariza A, Fürst CJ, Håkanson C. Palliative care during the final week of life of older people in nursing homes: A register-based study. Palliat Support Care 2017; 15(4):417-424.

10. Nicholson C, Davies JM, George R, Smith B, Pace V, Harris L, Ross J, Noble J, Hansford P, Murtagh FEM. What are the main palliative care symptoms and concerns of older people with multimorbidity? Ann Palliat Med 2018; 7(Supl. 3):S164-S175.

11. Penders YW, Gilissen J, Moreels S, Deliens L, Van den Block L. Palliative care service use by older people: Time trends from a mortality follow-back study between 2005 and 2014. Palliative medicine 2018; 32(2):466-475.

12. Floriani CA, Schramm FR. Desafios morais e operacionais da inclusão dos cuidados paliativos na rede de atenção básica. Cad Saude Publica 2007; 23(9):20722080.

13. Brasil. Portaria no 2.436, de 21 de setembro de 2017 . Estabelece a revisão de diretrizes da Política Nacional de Atenção Básica (PNAB), no âmbito do Sistema Único de Saúde (SUS). Diário Oficial da União 2017; 22 set.

14. Gadamer HG. Verdade e método. Petrópolis: Vozes; 1997

15. Minayo MCS. Amostragem e saturação em pesquisa qualitativa: consensos e controvérsias. Revista Pesquisa Qualitativa 2017; 5(7):1-12.

16. Marshall MN. Sampling for qualitative research. Fam Pract 1996; 13(6):522-526. 
17. Brasil. Ministério da Saúde (MS). Portaria no 2.527, de 27 de outubro de 2011: Redefine a Atenção Domiciliar no âmbito do SUS. Diário Oficial da União 2011; 28 out.

18. Bardin L. Análise de Conteúdo. Lisboa: Ed. 70; 2008

19. World Health Organization (WHO). Palliative Care. Geneva: WHO; 2018.

20. Cunha GT, Campos GWS. Apoio matricial e atenção primária em saúde. Saúde Soc 2011; 20(4):961-970.

21. Rego S, Palácios M. A finitude humana e a saúde pública. Cad Saude Publica 2006; 22(8):1755-1760

22. Stein E. História e ideologia. Porto Alegre: Editora Movimento; 1999.

23. Vieira RR, Robortella AR, De Souza AB, Kerr GS, Janaine Aline Camargo De Oliveira JAC. Vida e morte na atenção primária à saúde: reflexões sobre a vivência do médico de família e comunidade ante a finitude da vida. Revista Brasileira de Medicina de Família e Comunidade 2016; 11(38):1-7.

24. Schramm FR. Morte e finitude em nossa sociedade: implicações no ensino dos cuidados paliativos. Revista Brasileira de Cancerologia 2002; 48(1):17-20.

25. Warnke G. Gadamer: Hermeneutics, tradition, and reason. Palo Alto: Stanford University Press; 1987.

26. Gadamer HG. O caráter oculto da saúde. Petrópolis: Editora Vozes; 2006.

27. Silva CFD, Souza DM, Pedreira LC, Santos MRD, Faustino TN. Concepções da equipe multiprofissional sobre a implementação dos cuidados paliativos na unidade de terapia intensiva. Cien Saude Colet 2013; 18(9):2597-2604.

28. Silva DIS, Silveira DT. Cuidados paliativos: desafio para a gestão e políticas em saúde. Revista Eletronica Gestão \& Saúde 2015; 6(1):501-513.

29. Oliveira SG, Kruse MHL. Melhor em Casa: dispositivo de segurança. Texto \& contexto enfermagem 2017; 26(1):e2660015.

30. Peters L, Cant R, Sellick K, O'Connor M, Lee S, Burney $\mathrm{S}$, Karimi L. Is work stress in palliative care nurses a cause for concern? A literature review. Int J Palliat Nurs 2012; 18(11):561-567.

31. Stewart AL, Teno J, Patrick DL, Lynn J. The concept of quality of life of dying persons in the context of health care. J Pain Symptom Manage 1999; 17(2):93-108.

32. Hales S, Zimmermann C, Rodin G. The quality of dying and death. Arch Intern Med 2008; 168(9):912-918.
33. Hales S, Chiu A, Husain A, Braun M, Rydall A, Gagliese L, Rodin G. The quality of dying and death in cancer and its relationship to palliative care and place of death. J Pain Symptom Manage 2014; 48(5):839-851.

34. Silva CG, Cota LI, Vieira RO, De Arrazão VD, Cyrino LAR. Doenças terminais, conhecimento essencial para o profissional da saúde. Psicologia Argumento 2013; 31(72):137-144.

35. Boff L. Saber cuidar: ética do humano, compaixão pela terra. Petrópolis: Editora Vozes; 2003.

36. Jardim J, Pereira A. Competências pessoais e sociais. Guia prático para a mudança positiva. Porto: Asa Editores; 2006.

37. Bierhals CCBK, Santos NO, Fengler FL, Raubustt KD, Forbes DA, Paskulin LMG. Necessidades dos cuidadores familiares na atenção domiciliar a idosos. Rev Latino-Americana de Enfermagem 2017; 25:e2870.

38. Albuquerque ABB, Bosi MLM. Visita domiciliar no âmbito da Estratégia Saúde da Família: percepções de usuários no Município de Fortaleza, Ceará, Brasil. Cad Saude Publica 2009; 25(5):1103-1112.

Artigo apresentado em 03/05/2018

Aprovado em 23/10/2018

Versão final apresentada em 25/10/2018 


\section{ERRATA}

p. 2063

onde se lê:

The significance of home care in caring for the elderly in their twilight years: the human perspective of the SUS professional

\section{leia-se:}

The meanings of home care in caring for the older person at end-of-life: the compassionate perspective of the professionals from SUS

\section{onde se lê:}

Abstract The access to healthcare of elderly individuals in their twilight years needing palliative care in the home serve as a wake-up call in terms of current healthcare programs and strategies.

\section{leia-se:}

Abstract The access to healthcare of older people in the end of their lives needing palliative care in the home serve as a wake-up call in terms of current healthcare programs and strategies.

p. 2065

onde se lê:

Universidade XX

leia-se:

Universidade Federal do Rio Grande do Sul 